Editorial

\title{
North Sea coastal ecology: Preface
}

Worldwide, the marine environment and especially coastal zones show strong spatial and temporal variability in physical conditions and ecology, and are at the same time affected by a variety of anthropogenic influences.

These waters include the European North Sea, a semi-enclosed shelf sea surrounded by the United Kingdom, Belgium, the Netherlands, Germany, Denmark and Norway. Long-term (millennia) inhabitation of these coastal areas has resulted in a strong anthropogenic footprint such as polluted waters, deteriorated marine habitats and depleted fish stocks. Ongoing and future impacts include the combined effects of climate change (e.g., warming, acidification, deoxygenation), and modern contaminants (e.g. microplastics).

The consequences of human impacts on the North Sea proper is determined, amongst others, by the interactions between the central basin and the surrounding intertidal basins, estuaries and tributaries at one hand and the Atlantic Ocean at the other.

Over the years, symposia have been held and numerous papers were published focusing on various aspects of the North Sea dynamics. This volume of the Journal of Sea Research does not intend to summarize the present state of knowledge concerning North Sea ecology, but should be considered as a broad (though not exhaustive) overview of ongoing research especially in the coastal zone and with an emphasis on spatial and temporal variabilities, with the aim to sketch some lines of future research based on in total 19 contributions.

Theo Gerkema

NIOZ Royal Netherlands Institute for Sea Research, Department of Estuarine and Deltaic systems, Utrecht University, P.O. Box 140, 4400 AC Yerseke, The

Netherlands

Utrecht University, P.O. Box 140, 4400 AC Yerseke, The Netherlands

Catharina J.M. Philippart, Henk W. van der Veer* NIOZ Royal Netherlands Institute for Sea Research, Department of Coastal systems, Utrecht University, PO Box 59, 1790 AB Den Burg, Texel, The Netherlands

Utrecht University, P.O. Box 59, 1790 AB Den Burg, Texel, The Netherlands E-mail address: Henk.van.der.Veer@nioz.nl

\footnotetext{
* Corresponding author.
} 